\title{
ASSESSMENT OF EMERGENCY MEDICAL SERVICES IN THE ASHANTI REGION OF GHANA
}

\author{
N.K. MOULD-MILLMAN ${ }^{1}$, R. OTENG ${ }^{2}$, A. ZAKARIAH ${ }^{3}$, M. OSEI-AMPOFO ${ }^{4}$, G. ODURO ${ }^{4}$, W.

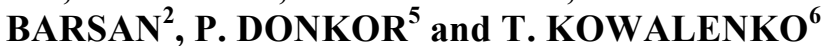 \\ ${ }^{1}$ University of Colorado, School of Medicine, Department of Emergency Medicine, Aurora, USA, ${ }^{2}$ University \\ of Michigan, Department of Emergency Medicine, Ann Arbor, USA, ${ }^{3}$ National Ambulance Service, Republic \\ of Ghana Ministry of Health, Accra, Ghana, ${ }^{4}$ Komfo Anokye Teaching Hospital, Accident and Emergency \\ Centre, Kumasi, Ghana, ${ }^{5}$ Kwame Nkrumah University of Science and Technology, Kumasi, Ghana, ${ }^{6}$ Oakland \\ University William Beaumont School of Medicine, Department of Emergency Medicine, Royal Oak, USA
}

DOI: $h t t p: / / d x . d o i . o r g / 10.4314 / g m j . v 49 i 3.1$

Corresponding author: Dr. N.K. Mould-Millman

Email: Nee-Kofi.Mould-Millman@UCDenver.edu

Conflict of Interest: None declared

\section{SUMMARY}

Background: We aimed to assess the structure, function and performance of Ashanti Region's emergency medical services system in the context of the regional need for prehospital emergency care.

Design: A mixed-methods approach was employed, using retrospective collection of quantitative data and prospectively gathered qualitative data. Setting - pertinent data were collected from Ghanaian and international sources; interviews and technical assessments were performed primarily in the Ashanti Region of Ghana.

Participants: All stakeholders relevant to emergency medical services in the Ashanti Region of Ghana were assessed; there was a special focus on National Ambulance Service (NAS) and Ashanti Region healthcare personnel.

Intervention: This was an observational study using qualitative and quantitative assessment techniques.

Main outcome measures: The structure, function and performance of the Ashanti emergency medical services system, guided by a relevant technical assessment framework.

Results: NAS is the premier and only true prehospital agency in the Ashanti Region. NAS has developed almost every essential aspect of an EMS system necessary to achieve its mission within a low-resource setting. NAS continues to increase its number of response units to address the overwhelming Ashanti region demand, especially primary calls. Deficient areas in need of development are governance, reliable revenue, public access, community integration, clinical care guidelines, research and quality assurance processes.

Conclusions: The Ashanti Region has a growing and thriving emergency medical services system. Although many essential areas for development were identified, NAS is well poised to meet the regional demand for prehospital emergency care and transport.
Keywords: EMS, prehospital, ambulance, emergency, Ghana, Africa

\section{INTRODUCTION}

African nations bear a disproportionate global burden of death and disability attributable to traumatic and other emergency conditions. ${ }^{1,2}$ Although epidemiologic data specific to emergency medical conditions in African countries is lacking, international health experts suggest that many leading conditions may present emergently in their acute phase. ${ }^{3}$ In Ghana, the population of the Ashanti Region experiences high morbidity and mortality predominantly from traumatic injuries, obstetric complications, cardiovascular, respiratory, neurologic and diabetic-related emergencies. ${ }^{4,5,6}$ Previous Ghanaian studies have demonstrated the following contributing prehospital factors: barriers to accessing timely emergency care, poor communication, use of informal modalities for emergency transportation, delayed inter-hospital transfers, and the lack of formal systems of prehospital care. ${ }^{6,7,8}$

In 2004, the Government of the Republic of Ghana commissioned a National Ambulance Service (NAS), operated by the Ministry of Health $(\mathrm{MOH})$. The charter of NAS is to improve timely and safe prehospital response and medical care to the population of Ghana. 6,9 NAS reports suggest that by 2010 there was at least one NAS ambulance with trained emergency medical technicians (EMTs) in every region of Ghana, including the Ashanti Region. ${ }^{9}$ NAS is a rapidly expanding Emergency Medical Services (EMS) agency, aggressively attempting to meet the prehospital demand of the Ghanaian population.

Formal ambulance services are delivered by two parallel, government-run, systems: NAS and a hospital- 
operated Facility-Based Ambulance Service (FBAS). FBAS ambulances operated out of approximately twelve Ashanti Region district hospitals for conducting urgent or emergent inter-facility transfers to the Regional Hospital or a teaching tertiary care hospital. A substantial "informal" system exists which conducts the majority of prehospital emergency transportation in the Ashanti Region, thereby supplementing FBAS and NAS efforts. This informal system comprises good Samaritans and passersby transporting patients via private and commercial vehicles to the nearest hospital. $^{6,7,8}$

Unfortunately, no medical care is delivered during informal prehospital transportation, and coupled with inappropriate selection of destination facilities, this adversely contributes to the overall prehospital morbidity and mortality. ${ }^{8}$ The extent to which the formal and the informal transport system contribute to morbidity and mortality remain unknown. ${ }^{6,10,11}$ In the Ashanti Region, patients requiring emergency inter-facility referrals are predominantly transported to a modern, 100 bed, National Accident and Emergency Center (AEC) at Komfo Anokye Teaching Hospital (KATH), in the regional capital, Kumasi. Built in 2008, the KATH AEC is home to the first emergency medicine (EM) residency training program in Ghana. ${ }^{12}$ Subspecialty care at KATH includes orthopedic surgery, trauma and burn care, and various medical and surgical sub-specialties.

The mission of a formal EMS system to reduce death and disability can be furthered through integrating the work of trained prehospital personnel (providing field care and emergency medical transport) with a coordinated community-based response. ${ }^{13,14}$ Growing evidence suggests that effective prehospital trauma care systems confer a survival benefit to patients with nontraumatic emergency conditions, due to shared principles of timely, effective and integrated care. ${ }^{13,14}$ This study is therefore grounded on the premise that EMS systems, if effectively implemented in resourceconstrained settings, can augment the emergency care system and improve patient outcomes.

\section{Objectives}

The objective of this study is to assess the structure, function and performance of Ashanti Region's EMS system in the context of the regional need for prehospital emergency care.

\section{METHODS}

\section{Approach}

This assessment employed a mixed-methods approach, using retrospective collection of quantitative data and prospectively gathered qualitative data.
The assessment team comprised local and international EMS experts (NMM, AZ) and emergency medicinetrained (NMM, RO) physicians with several years of in-country emergency care experience. The assessment was conducted from May 2012 to December 2012.

No standardized, widely-accepted method exists for conducting EMS system assessments, in either developed or developing settings. To provide a framework for conducting this assessment, essential elements of low-resource EMS systems were identified using sources of international expert recommendations and published studies; ${ }^{13-17}$ these elements were integrated into a conceptual model previously devised and applied by the lead author (NMM) in similar LMIC EMS system assessments (Figure 1). The assessment model includes six key categories (governance, finance, public access, prehospital providers, operations, and system-unifying components) and a total of 28 elements.

Figure 1 Essential Elements of a Low-Resource EMS System

EsSential ElementS of AN EMERgency Medical Services (EMS) SYSTEM

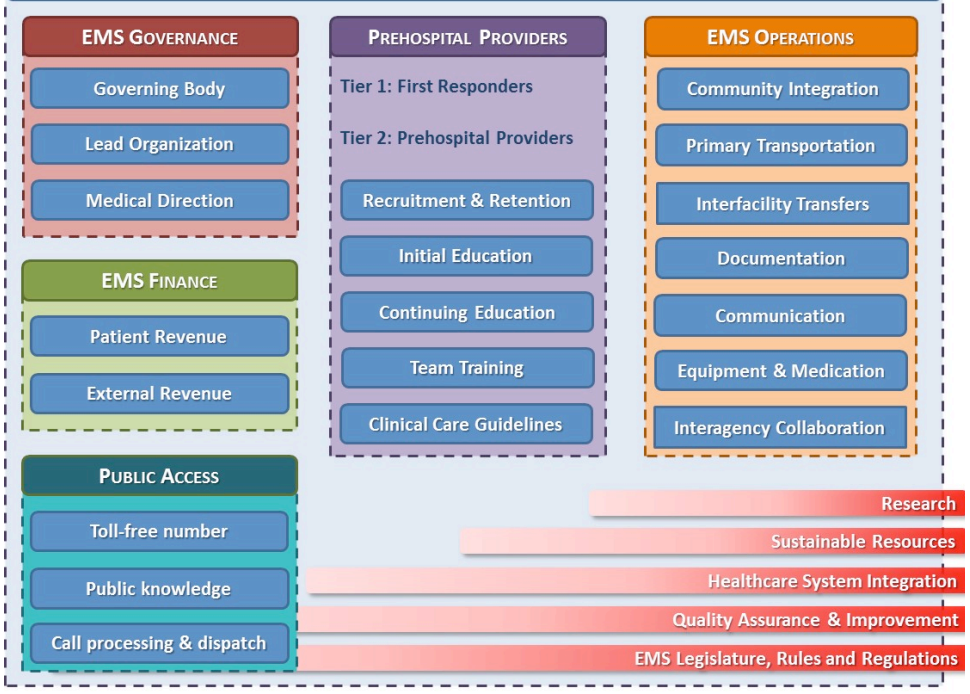

\section{Quantitative Assessment}

To retrieve epidemiologic data to facilitate quantifying the burden of acute and emergency disease in the Ashanti Region of Ghana, non-peer reviewed 'gray' literature were reviewed from the following publically available sources: WHO (Geneva, Switzerland); Ghana Health Service, Ashanti Regional Directorate (Kumasi, Ghana); National Ambulance Service (Accra, Ghana); National Disaster Management Organisation (Kumasi, Ghana); Ghana Road Traffic and Safety Commission (Kumasi, Ghana); and the Komfo Anokye Teaching Hospital (Kumasi, Ghana). 
Ashanti Region priority conditions were identified i.e. those which contribute significantly to the national and Ashanti regional burden of death and disability.

These priority conditions, and their associated burden of disease, framed the regional demand for EMS services.

To characterize the capacity of the Ashanti Region EMS agencies to meet the demand, EMS structure and functional data were obtained from two sources: NAS and FBAS. NAS annual reports from 2008 to 2011 were valuable sources of data (Courtesy Dr. Ahmed Zakariah, NAS). FBAS data were collected from Ashanti Regional Health Directorate personnel (Courtesy Dr. Aaron Ofei, Ghana Health Service). All data were analyzed in the context of the assessment framework depicted in Figure 1.

\section{Qualitative assessment}

Semi-structured interviews were conducted with key stakeholders and personnel from various agencies and organizations, including government, private and academic healthcare facilities, public safety, disaster management, and public health. Interviews were also conducted with administrative and clinical personnel from both NAS and FBAS systems. Three of the highest volume referring healthcare facilities in the Ashanti Region (governmental and non-governmental) were selected (from KATH annual reports) for site visits, including personnel interviews.

\section{Data Analysis}

Descriptive statistics were performed for quantitative data. The qualitative data was transcribed, collated and integrated with quantitative data to provide explanations of numerical findings. The level of development of each essential EMS element was assessed by considering the structural and functional aspect of those elements in relationship to the local demand for EMS services. Within each of the six essential EMS categories, the authors adapted a previously-applied, five-tier technique of grading the level of development of each element within that category as follows:

\begin{tabular}{|l|l|}
\hline $\begin{array}{l}\text { Well } \\
\text { developed }\end{array}$ & $\begin{array}{l}\text { Highest grade, describing a well-functioning EMS } \\
\text { element completely satisfying its intended role with- } \\
\text { in the local EMS system }\end{array}$ \\
\hline $\begin{array}{l}\text { Mostly } \\
\text { developed }\end{array}$ & $\begin{array}{l}\text { Better than "partially developed," but the element is } \\
\text { not completely or "well developed" }\end{array}$ \\
\hline $\begin{array}{l}\text { Partially } \\
\text { developed }\end{array}$ & $\begin{array}{l}\text { Neutral grade, describing an EMS element pos- } \\
\text { sessing an equal balance of existing and absent }\end{array}$ \\
\hline
\end{tabular}

\begin{tabular}{|l|l|}
\hline & $\begin{array}{l}\text { structural and/or functional features, in the local } \\
\text { context of the EMS system }\end{array}$ \\
\hline $\begin{array}{l}\text { Minimally } \\
\text { developed }\end{array}$ & $\begin{array}{l}\text { An EMS element that is less than "partially devel- } \\
\text { oped" but not totally absent }\end{array}$ \\
\hline $\begin{array}{l}\text { Non- } \\
\text { developed }\end{array}$ & $\begin{array}{l}\text { Lowest grade possible, assigned if an EMS element } \\
\text { is completely absent in structure and/or function }\end{array}$ \\
\hline
\end{tabular}

\section{Ethical Review}

Study protocols and procedures were approved and conducted in compliance with the Committee on $\mathrm{Hu}-$ man Research Publication and Ethics, School of Medical Sciences, Kwame Nkrumah University of Scienceand Technology and the University of Michigan Institutional Review Board for Human Subjects guidelines.

\section{RESULTS}

Over thirty personnel were interviewed from institutions and agencies, including: National Ambulance Service (Director, Finance Manager, Operations and Logistics Manager, Ashanti Region Medical Director, Ashanti Region Medical Coordinator, Ashanti NAS EMTs, NAS Ashanti Region Control Room dispatch officers), Ashanti Regional Health Directorate (Regional Health Minister, Institutional Data Management Staff), Ghana Red Cross Society (Ashanti Region Coordinator), and the Ashanti Region Head of the National Disaster Management Organization (NADMO).

Government and charity healthcare facilities visited included Manhyia Hospital (government districthospital), St Patrick's and Holy Family Hospitals (nongovernmental, charity-funded); at these facilities Medical Superintendents, Facility Administrators, Heads of Departments, and clinical staff were interviewed. At KATH, the academic tertiary care center, AEC clinicians and staff, Obstetrics and Gynecology clinicians and staff, and Pediatric Emergency Unit staff were interviewed. Quantitative data was abstracted from all the sources indicated in the Methods section (above). Summaries of the Ashanti Region prehospital burden of disease (Table 1) and the EMS system assessment grading (Table 2 ) are located below.

\section{The Ashanti Region Burden of Disease}

Table 1: Ashanti Region Prehospital Burden of Disease: Includes selected acute and emergency conditions amenable to prehospital care and transportation. 
Table 1 Ashanti Region prehospital burden of disease

\begin{tabular}{|c|c|c|c|}
\hline INDICATOR & VALUE & YEAR & COMMENTS \\
\hline \multicolumn{4}{|l|}{ Ashanti Healthcare Resource Distribution } \\
\hline Population & $5,200,000$ persons & 2012 & Ghana Statistical Service \\
\hline Physician:population ratio & $1: 39,153$ & 2010 & Ghana Health Service, Ashanti Regional Directorate \\
\hline Nurse:population ratio & 1:7,215 & 2010 & Ghana Health Service, Ashanti Regional Directorate \\
\hline EMT:population ratio & $1: 52,000$ & 2012 & National Ambulance Service Report \\
\hline Healthcare facilities & 500 facilities & 2010 & Ghana Health Service \\
\hline Teaching, teritiary care hospital & 1 facilitiy & 2012 & Komfo Anokye Teaching Hospital \\
\hline District Hospitals & 27 faciltities & 2010 & Government owned and operated \\
\hline Sub-district hospitals and clinics & 302 facilities & 2009 & Government and private \\
\hline Mission hospitals & 85 facilities & 2009 & Charity or faith-based facilities \\
\hline District Hospitals & 27 faciltities & 2010 & Government owned and operated \\
\hline \multicolumn{4}{|l|}{ Injuries in the Ashanti Region } \\
\hline Annual road traffic collissions & 1944 events & 2010 & 2010. $16.6 \%$ of national burden \\
\hline Road traffic collission fatalities & 454 persons & 2010 & Death within 30 days of the event. $20.7 \%$ of national \\
\hline Road traffic collission injuries & 3298 persons & 2010 & $22.1 \%$ of national, Building and Road Research Institute \\
\hline Pedestrians struck, fatal & 193 persons & 2010 & $42.5 \%$ of national, Building and Road Research Institute \\
\hline Pedestrians struck, injured & 560 persons & 2010 & $35.8 \%$ of national, Building and Road Research Institute \\
\hline \multicolumn{4}{|l|}{ Maternal \& Neonatal Statistics, Ashanti Region } \\
\hline Komfo Anokye Teaching Hospital (KATH) Maternal Mortality & 114 cases & 2009 & KATH Annual Report \\
\hline Institutional Maternal Mortality Rate & 932 per 100,000 & 2009 & KATH Annual Report \\
\hline Proportion of deaths with 24 hours of arrival & $60 \%$ & 2009 & KATH Annual Report \\
\hline Admissions for eclampsia/pre-eclampsia & 622 cases & 2009 & KATH Annual Report \\
\hline Neonatal sepsis & 956 cases & 2009 & KATH Annual Report \\
\hline Ghana Health Services Facilities, Maternal Mortality & 61 cases & 2011 & GHS Ashanti Region data \\
\hline Post-partum hemorrhage & $64 \%$ & 2011 & GHS Ashanti Region data \\
\hline Eclampsia and pre-eclampsia deaths & $20 \%$ & 2011 & GHS Ashanti Region data \\
\hline \multicolumn{4}{|l|}{ Komfo Anokye Teaching Hospital (KATH) Burden of Disease } \\
\hline Accident and Emergency Center (AEC) annual volume & 29,441 cases & 2009 & KATH A\&E data \\
\hline Percentage of all referrals arriving at AEC by ambulance & $30 \%$ & 2013 & Mould-Millman, et al. AfJEM. Per KATH 2011 AEC data \\
\hline Percentage of all patients at AEC arriving by ambulance & $15 \%$ & 2013 & Mould-Millman, et al. AfJEM. Per KATH 2011 AEC data \\
\hline Injury-related complaint amongst all patients to AEC & $41 \%$ & 2013 & Mould-Millman, et al. AfJEM. Per KATH 2011 AEC data \\
\hline Fraction of high acuity ambulance-arrivals (SATS orange $\&$ red) & $34 \%$ & 2013 & Mould-Millman, et al. AfJEM. Per KATH 2011 AEC data \\
\hline Institutional deaths (sentinel events amenable to prehospital care) & 686 cases & 2009 & KATH Annual Report \\
\hline Cardiovascular event & $38 \%$ & 2009 & KATH Annual Report \\
\hline Pneumonia & $17 \%$ & 2009 & KATH Annual Report \\
\hline Diabetes & $13 \%$ & 2009 & KATH Annual Report \\
\hline HIV/AIDS & $11 \%$ & 2009 & KATH Annual Report \\
\hline Neonatal sepsis & $10 \%$ & 2009 & KATH Annual Report \\
\hline Heart failure & $10 \%$ & 2009 & KATH Annual Report \\
\hline \multicolumn{4}{|l|}{ Regional Burden of Disease } \\
\hline Total outpatient referrals & $1,000,000$ cases & 2010 & Ghana Health Service, Ashanti Regional Directorate \\
\hline Total inpatient admission volume & 170,000 & 2010 & Ghana Health Service, Ashanti Regional Directorate \\
\hline Inpatient admission rate & $42 \%$ & 2010 & Ghana Health Service, Ashanti Regional Directorate \\
\hline FREQUENCY OF ACUTE EVENTS AMENABLE TO PREHOSP & 23,500 events/year & & 1 acute event per 221 persons within the population \\
\hline
\end{tabular}

\section{Ashanti Region EMS Assessment Grading}

EMS Governance: Lead Organization - mostly developed. Prehospital experts from the WHO encourage one lead agency to be responsible for providing and coordinating prehospital care in a low-resource jurisdiction $^{14}$.

1. NAS was commissioned in 2004 as a public agency of the MOH.

2. Mission of NAS is to provide Ghanaians free access to safe and timely prehospital care.
3. There was a well-defined organizational structure led by an Executive Director (Figure 2).

4. Ashanti NAS regional management included a physician Regional Medical Coordinator (responsible for day-to-day administration, operations, and logistics) and a physician Regional Medical Director (to oversee clinical care and education).

5. Administrative authority resided in Accra, thereby slowing NAS financial and operational activities in the Ashanti Region. 
Table 2 Summary of Ashanti Region EMS Assessment Grading

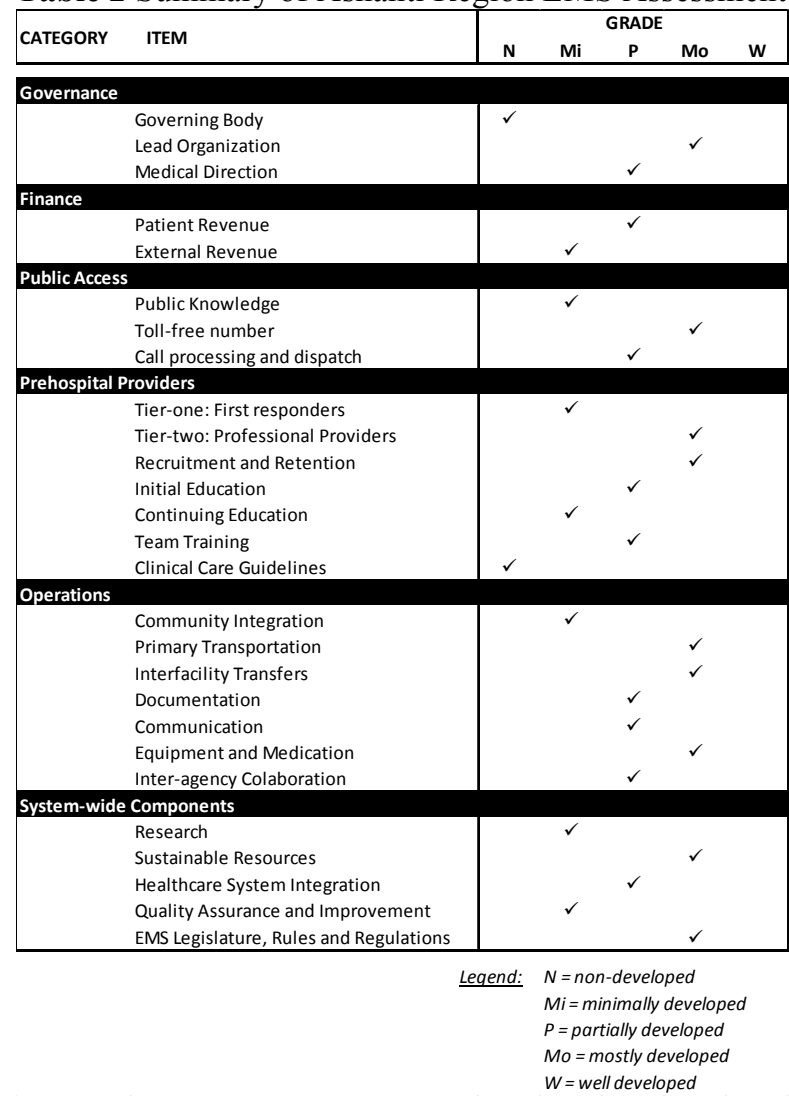

Figure 2 NAS 2012 Organogram

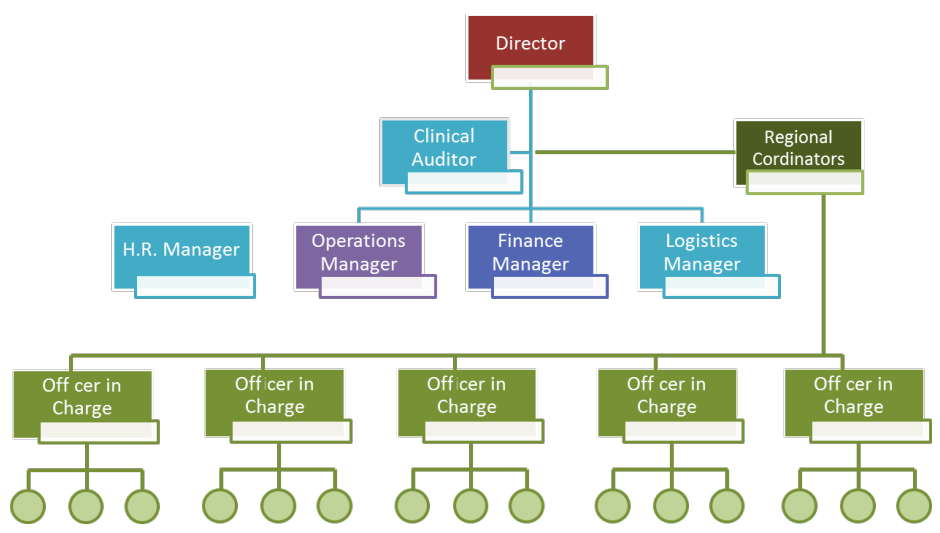

EMS Governance: Governing Body - non-developed. Conceptually, a governing body provides oversight, guidance and ensures accountability of the EMS agency.

1. Ambulance Council of Ghana, was enacted in 2010, but still awaited formation in 2012 .

2. No governing body existed to oversee and regulate the practice of prehospital care in Ghana.
3. Commissioning planned for 2014 (as of 22-January2015, the Ambulance Council remained noncommissioned).

EMS Governance: Medical Direction - partially developed.

An EMS Medical Director plays a critical role by providing clinical and educational oversight for the EMS agency which safeguards the appropriate provision of prehospital clinical care ${ }^{14}$.

1. Ashanti was the only region in Ghana with a NAS EMS Medical Director.

2. No clinical performance reviews or educational assessments of clinicians by Medical Director.

3. Ashanti Medical Director occasionally provided online (i.e. phone- or radio-based) medical control and guidance for medics.

4. No off-line medical control (i.e. pre-written clinical guidance documents) available.

EMS Finance: patient generated revenue - partially developed. Non-patient generated revenue - minimally developed.

Leading global and public health econometrists have emphasized that the provision of out-of-hospital emergency care in sub-Saharan Africa can be a relatively cost-effective intervention to reduce morbidity and mortality $^{3,13}$. However, EMS agencies have to delicately balance delivering a free public service with operational costs.

1. NAS had a well-established annual operating budget, annually pre-approved by $\mathrm{MOH}$.

2. 2012 approved budget was approximately 4.96 million US dollars: Government of Ghana (10\%), donor and bank funds $(7 \%)$ and the National Health Insurance System (NHIS) (83\%). 9

3. Only $60 \%$ of NHIS-pledged funds were disbursed to NAS in 2012 (deficit carried over to 2013).

4. In Ashanti, NAS offered free service to patients with emergency conditions. Non-emergency or elective ambulance transportation was conducted at reasonable fee-for-service basis.

5. The fee structure was unpublished and unknown to the Ashanti medical and lay community.

6. NAS discussing with NHIS to explore more predictable and equitable models of reimbursement, including capitation and episode-of-care.

EMS Access: Public Knowledge - minimally developed. Toll-free Number - moderately developed.

Public access to EMS systems is critical to ensure that citizens and healthcare personnel can reach EMS resources for medically-appropriate emergency transportation. $^{7}$ 
The WHO advocates that one well-publicized, toll-free, number be made publically available by the EMS agency. $^{14}$

1. A national toll-free, three-digit number (1-9-3) existed for several years.

2. Four out of five cellular companies in Ghana in 2012 offered this toll-free service.

3. There was no legislature mandating this as a free or compulsory service.

4. Interviews suggested poor knowledge of 1-9-3 amongst the Ashanti lay population, but high knowledge within the healthcare community. This necessitates a more formal assessment.

5. NAS has elected not to embark on mass public advertising, given that ensuing surge in calls would overwhelm the agency and cause public loss of trust.

6. In $2012,85 \%$ of $1-9-3$ calls in Ashanti originated from healthcare facilities, mostly to KATH in $\mathrm{Ku}-$ masi.

7. NAS strengthened relationships with Ashanti healthcare facilities to help address the large burden of acute disease and facilitate urgent and emergent inter-hospital transfers.

EMS Access: Call processing and dispatch - partially developed. Emergency medical dispatch provides a means of algorithmic telephone-based triaging of patients, dispatching appropriate EMS resources to the incident scene, and providing pre-arrival instructions to aid callers during medical emergencies.

1. The Ashanti Region NAS Communications Center, one of only two nationally, was located at KATH in Kumasi. 1-9-3 calls from Ashanti northwards were received and processed there.

2. It was staffed by a dedicated team of NAS EMTs, 24 hours per day, 7 days a week, all year.

3. There was no public safety answering point (PSAP) to which the 1-9-3 calls were initially routed, which is advantageous by reducing the call-to-dispatch interval.

4. There was a declining annual call volume to the Communications Center from $2007(\sim 3,200)$ to $2012(\sim 1,500)$, partially attributed to an aging fleet of ambulances overwhelmed by the demand.

5. Each of the 5 major cellular companies had a dedicated receiver in the NAS communications center; during simultaneous calls, the dispatch officer randomly prioritized calls.

6. A large number of hoax calls were received to the dispatch center, for unclear, unstudied reasons. There were no ambulance dispatches for hoax calls.

7. No formal, scripted, algorithmic call-processing or prioritization existed; the NAS dispatch officers performed two important tasks during call-taking: identified the need for an emergency medical response, and identified the patient location. If neither could be successfully ascertained, the call was terminated without an ambulance dispatch.

8. No system status monitoring existed, hence ambulance activities could not be geospatially or temporally represented in real-time.

Prehospital Providers: Tiers of Providers - minimally developed. The WHO, World Bank, and African Federation for Emergency Medicine advocate for two tiers of trained out-of-hospital emergency response providers in low-resource settings: community-based first responders (tier-one) and professional prehospital providers (tier-two $)^{11,14}$. While tier-one providers technically fall outside the purview of the EMS agency, experts encourage their integration with formal agencies, especially in training and medical responses.

1. NAS did not formally recruit, employ or train first responders, in Ashanti or elsewhere.

2. NAS collaborated with first responders, including Ghana Red Cross Society (GRCS), especially in responses to road traffic collisions and pre-planned mass gathering events.

3. NAS trained and employed 112 EMTs (92 basic and 20 advanced), operating 12 ambulances out of 5 ambulance stations in the Ashanti Region.

Prehospital Providers: Recruitment and Retention mostly developed. A reliable and continuous supply of qualified prehospital personnel is critical to ensure sustained growth of EMS human resources and EMS operational growth.

1. NAS EMT recruitment occurred nationally and was coordinated by the Human Resources manager.

2. It occurred on an on-going cycle; as one class of EMTs was undergoing training (typically 1-2 years), a new class was being recruited.

3. NAS basic EMTs (EMT-B's) minimum education requirement was a secondary school diploma.

4. NAS advanced EMTs (EMT-A's) were recruited with a minimum of a university degrees.

5. Prior experience in the medical field was not a prerequisite for either level of EMT.

6. EMT recruits were screened with interviews and health assessments, and then hired as government healthcare trainees.

7. Following graduation, EMTs were deployed nationally, but could request specific posting preferences, which increased job satisfaction.

8. EMTs cited limited potential for promotion as dissatisfying factor. In response, NAS leadership offered educational upgrades to promote the longestserving EMT-B's to EMT-A's.

9. As of 2012, NAS had successfully completed five rounds of EMT recruitment and training.

10. The national and Ashanti Region attrition rate was less than $5 \%$ annually. 
Prehospital Providers: Initial Education - partially developed. In 2008, NAS adapted a United States standardized EMT educational curriculum (core content was commiserate with US NREMT certificate level of EMT). In 2010, this curriculum was modified for training EMT-A's. All EMTs are trained in an internal, NAS training academy.

1. A new NAS training academy will open in Nkenkansu, Ashanti Region (in 2012)

2. In 2012, the 12-month training curriculum included:

a. 6 months of class-room based didactic lectures and skills workshops,

b. 3 months of an ambulance-based apprenticeship, and

c. 3 months of hospital-based clinical rotations nationwide.

3. The curriculum was purposefully split into 2 semesters:

a. Semester I (EMT Foundations I) included lectures in EMS operations, EMT responsibilities, anatomy and physiology, patient history and physical exam techniques, infection prevention and control, and several patient complaint-based modules.

b. Modules covered in Semester II (Foundations II) expanded on several modules from Semester I and emphasized pathophysiology and symptom-based prehospital management.

4. At the time of this assessment, there were no EMS physicians, or educators specifically qualified to deliver EMS education in Ghana.

5. To be adaptable and sustainable, the didactic curriculum was delivered by faculty educators in diverse specialties from various Ghanaian medical education institutions.

6. A wide breath of general medical content was taught, with only a light focus on high-yield prehospital or emergency care content.

7. Many healthcare professionals interviewed, with frequent EMT contact, urged more detailed prehospital education.

8. EMTs unanimously reported suboptimal clinical experiences due to poor clinical mentorship and supervision and significant heterogeneity in the quality and breath of clinical rotations.

9. The 3-month ambulance apprenticeships, despite absence of qualified EMS field training officers, provided their richest training experiences.

10. Upon completion of both semesters, no comprehensive EMS-specific competency-based cognitive, affective or skills testing were conducted.

11. No certification body existed to offer independent assessment of the prehospital knowledge and skills of NAS EMT graduates.
Prehospital Providers: Continuing Education - minimally developed. Knowledge and skills decay have been demonstrated to occur among healthcare and prehospital workers in 3-9 month intervals.

1. NAS EMTs received refresher training approximately once or twice annually.

2. There is no formalized, structured, continuing medical educational curriculum or requirements.

3. Courses in 2012 included modified prehospital trauma life support (PHTLS), basic life support (BLS), essentials of prehospital documentation, and refresher training in vital signs.

4. A handful of Ashanti EMTs were able to participate.

5. Instructors were mostly international visitors specialized in emergency and prehospital care, only few with an in-depth appreciation of the local prehospital and emergency care system.

6. A trauma care assessment indicated low knowledge and skills of essential prehospital knowledge and skills; attitudes towards care were positively high ${ }^{18}$. A similar assessment of Ashanti EMTs was not performed due to logistical issues.

Prehospital Providers: Team Training - partially developed. Emergency care occurs on a continuum and involves multiple providers serving critical roles at different times in different locations. An EMS provider's ability to understand and navigate through this chain of care may improve prehospital system efficiency and patient care $6,7,10,11,13,14$. To achieve this, EMS providers must be training alongside personnel across multiple disciplines, thereby improving prehospital coordination, communication, clinical care and transport of critically ill or injured prehospital patients.

1. NAS EMTs were trained to work closely with ambulance crew members and with dispatch officers.

2. During clinical rotations, EMTs received exposure to in-hospital care team dynamics, which proved useful in selecting destination facilities and handing off patients to in-hospital providers.

3. EMT verbal handoff and written communication were frequently criticized during interviews with KATH nurses and physicians.

4. To address this, a template NAS handoff tool was launched during a national train-the-trainer program in late 2012.

5. While Ashanti NAS EMTs had occasional out-ofhospital on-the-job exposure to other volunteer and professional groups (e.g. during mass-gathering events), no pre-planned cross-training activities occurred with groups such as GRCS, Ghana Police or National Fire Service.

Operations: Community Integration - minimally developed. International prehospital experts have recommended integration of EMS operations into the nonmedical community to improve emergency care ${ }^{13,14}$. 
Examples include providing community-based first responders with basic first aid kits, or formally linking midwives and traditional birth attendants to EMS agencies by communication and transportation ${ }^{11}$.

1. Existing community-based first responder programs in Ashanti included GRCS volunteer response groups and first aid training programs through the Driver and Vehicle Licensing Authority.

2. Neither was formally linked with NAS operations or training in Ashanti.

3. The low proportion of calls to NAS originating from community members in 2011 was indicative of poor community integration.

4. The Ashanti leadership of NAS concentrated on improving community relationships and outreach.

Operations: Primary Transportation and Inter-facility Transfers - mostly developed. Primary transportation is needed to convey patients from the point of an injury or illness (e.g. at home or the roadside) to an appropriate healthcare facility. Providing safe, medicallyappropriate, emergency transportation is a critical operational component of any EMS system. Across subSaharan Africa, inter-facility transfers (transporting patients from smaller to better-resourced, more specialized facilities) are important, but consume large amounts of EMS resources 7,8,9,10,11,13,14,15.

1. In 2012, NAS conducted 7,810 patient transports nationally.

2. There were approximately 2,500 transports in Ashanti.

3. Of all national cases, 5,942 (76\%) were inter-facility transports.

4. Data in Table 1 indicate a much larger regional volume of acute and emergency conditions (in excess of 20,000 cases per year) appropriate for prehospital care and emergency transportation.

5. Average NAS Ashanti ambulance mission time (dispatch to back in service) was 2 hours and 58 minutes. Average response time was 27 minutes (dispatch to scene) and average scene time was 15 minutes. Reducing delays in patient hand-offs and wait times for diagnostics could improve regional mission times and increase ambulance availability.

Experts from the Disease Control Priorities in Developing Countries (2nd Edition) cite a minimum desired ratio of approximately 1 EMS unit (i.e. ambulance and crew) per 100,000 population, in low-resource settings ${ }^{13} .112$ EMTs staffed 16 ambulances.

1. The EMS unit to population ratio was approximately $1: 325,000$.

2. A minimum of 52 EMS units is recommended (5.2 million Ashanti population in 2012).
3. As of early 2012, there were 16 EMS units operating within the Ashanti Region; this gave an EMS unit deficit for the region of 36 .

4. In rural areas where ambulance access is difficult consideration should be given to providing alternate EMS vehicles such as motorcycles with cots, as successfully implemented in Malawi ${ }^{11}$.

5. Historically, a large "informal system" of prehospital transport has filled the unmet need by NAS.

6. This informal system includes the unsafe, but necessary, use of private and commercial vehicles to transport emergency patients to points of care, as is common in many other sub-Saharan settings $6,7,8,14$.

7. No medical care is delivered during informal prehospital transportation, which may adversely contribute to patients' prehospital morbidity and mortality.

Operations: Documentation - partially developed. Documentation of operational and clinical information is critical for EMS system analyses and quality improvement measures.

1. NAS had standardized, well-designed, pre-coded prehospital forms in use nationally:

a. Form 1 captured key response/transport times, patient demographics, clinical history and findings, interventions and destination data.

b. NAS Form 2 allowed coding of patient conditions and prehospital resources consumed during in patient care.

2. EMTs were not equipped to leave a duplicate Form 1 at the receiving facilities.

3. Forms 1 and 2 are batch-returned to the Accra headquarters weekly for data entry into an electronic database - there was no decentralized data entry.

4. No formal quality assurance process exists to ensure accurate or complete information.

5. An audit in Ashanti revealed that operational data (response times, patient demographics and hand-off information) were most frequently completed.

6. Medical data (clinical history, vital signs and focused physical exam findings) were frequently incomplete on Form 1.

7. Incident forms (to document vehicular collisions, infectious exposures or staff injuries) were unavailable during the assessment period.

Operations: Communication - partially developed.

Communication between field crews, dispatch personnel and hospital-based staff is critical to linking geographically-distributed EMS resources, thereby efficiently coordinating patient care and transport ${ }^{14}$.

1. NAS ambulances in Ashanti were equipped with two-way, portable, wireless (Global Open Trunking Architecture - GoTa) radios. 
2. Radios were used for communication with the dispatch center, for status and location updates and to help crews determine optimal patient destinations.

3. Staff at healthcare facilities accessed NAS resources by contacting the dispatch center through personal cellular telephones or land lines.

4. NAS ambulance crews in Ashanti were unable to provide pre-arrival notification and updates to hospital staff.

5. KATH AEC, pediatric emergency unit, and obstetrics and gynecology staff reported frequent unanticipated arrivals, which delayed patient handoffs and disrupted emergency center flow.

6. During ambulance-to-facility patient handoffs, no standard EMS procedure or script was used, often resulting in fragmented or partial reports by EMTs.

7. Occasionally, NAS ambulances were requested to continue to other destinations.

Operations: Equipment and Medication - mostly developed. Standards exist for on-board ambulance equipment and medications commensurate with the level of the treating providers. 14

1. As of 2012, NAS utilized a fleet of modern, newlyacquired, tropicalized, four-wheel, Volkswagen ambulances. Each contained separate patient care and driver compartments.

2. These vehicles, staffed by EMT crews, were appropriately equipped for basic life support (BLS).

3. EMS markings were prominently displayed, and blue lights and sirens were functional throughout the fleet.

4. Equipment on board included GoTa radios, pens, paper, fire extinguisher, disinfecting equipment (alcohol solution and cloth), sharps and waste containers, personal protective equipment (gloves, face mask, gowns), equipment to obtain vital signs (stethoscope, sphygmomanometer, pulse oximeter), basic airway supplies (manual and automatic suction, oral and nasal airways), resuscitative breathing equipment (bag valve mask, face mask, nasal cannulae), an automated external defibrillator, trauma supplies (rigid splints, cervical collars, and first aid kits), and extrication aids (rigid backboard and a patient stretcher).

5. Equipment was generally in good to excellent condition.

6. On-board medications included oxygen, oral glucose and Paracetamol (acetaminophen).

7. Given BLS designation, further suggested medications included intravenous normal saline, intravenous dextrose, intramuscular epinephrine, and inhaled albuterol.
Operations: Inter-agency co-operation - partially developed.

Inter-agency collaboration, especially around training and disaster planning, is important to maximize EMS operational success in routine or mass-casualty situations.

1. Ashanti Region NADMO indicated occasional meetings and activities with NAS, mostly around preventative efforts such as illegal mining activities and mass gathering events.

2. NAS also engaged the Kumasi Airport Authority, the GRCS and several healthcare facilities for coordinated medical responses during mass casualty incidents and motor vehicle collisions.

3. There was no on-going collaboration with military, private EMS agencies, the Regional Health authorities, industry, or educational institutions.

System-wide Components: Research - minimally developed. Elements of scientific research are critical, but do require expertise and resources, to help ensure sustained, effective development ${ }^{6,11}$.

1. There was no evidence of existing NAS-specific EMS research in the Ashanti Region.

2. No research priorities or agenda, regionally or nationally, existed.

3. Previous studies in Ashanti focused on patients' mode-of-arrival to healthcare facilities (primary transports and inter-facility transfers), without separating NAS-specific transportation ${ }^{6}$. Data suggests that referred or injured patients are twice as likely to arrive at KATH AEC by ambulance as non-referred or uninjured patients ${ }^{6}$.

4. Educational, clinical, cost-effectiveness and outcomes-based research is encouraged.

System-wide Components: Sustainable Resources mostly developed. In resource-constrained settings, EMS systems must thrive and grow despite financial and procurement challenges, often requiring the agency to find creative solutions ${ }^{14}$.

1. Administratively and operationally in 2012, NAS thrived and expanded its national footprint.

2. In Ashanti, NAS personnel successfully locally procured and replenished consumable and nonconsumable supplies e.g. splints, spine-boards, oxygen.

3. Maintenance of German Volkswagen ambulances proved slightly challenging, with the only workshop located in Accra.

4. Replacement of specialized parts, such as faulty sirens, required parts to be shipped from overseas, with associated delays.

5. The Ashanti Region relied on the NAS administrative headquarters to replace parts and vehicles. 
System-wide Components: Healthcare System Integration - partially developed. Successful integration of the EMS system into the local healthcare and emergency care system is mutually beneficial and can enhance overall patient care and EMS operations ${ }^{6,14}$.

1. NAS Ashanti Regional Medical Coordinator conducted facility-based outreach and education.

2. NAS ambulances were stationed at several healthcare facilities in Ashanti, especially highvolume referral centers, to facilitate prompt interfacility transports.

3. The Regional Minister of Health indicated the Ministry's preference to have all NAS ambulances stationed and managed by government-run facilities, specifically district-hospitals, to mitigate the unsafe and untimely regional referral system.

4. NAS played a critical role in supporting the Ashanti referral system.

5. The ease and frequency of NAS access by hospital personnel confirmed NAS' early and continued attempt to integrate into the regional healthcare system.

System-wide Components: Quality Assurance and Improvement - minimally developed. Quality assurance and quality improvement initiatives can and should be built around operational, educational and clinical aspects to ensure optimal and safe functioning of the EMS system ${ }^{18}$.

1. A national quality assurance program was piloted in Accra in 2012.

2. The program was launched on a platform of safe, quality, prehospital clinical care and educational quality assurance and improvement.

3. While there was an initial national scale-up effort, the program did not thrive nationally.

4. No other robust regional quality assurance efforts exist in Ashanti.

System-wide Components: EMS Legislature, Rules and Regulation - mostly developed. An empowering legal and regulatory environment is crucial for the successful, safe, formal practice of prehospital medicine by any EMS agency. This protects patients by ensuring only qualified and authorized personnel deliver prehospital care. It also enables the legal, legitimate practice of prehospital care by the EMS agency thereby safeguarding its administration and prehospital providers. 14

1. In 2013, a Health Facilities and Institutions Bill was enacted into law.

2. It established an Ambulance Council (awaiting formation on 22-January-2015) to regulate ambulance operations and the practice of prehospital medicine in Ghana.
3. The companion 2010 General Health Service Bill, which legally empowered the publicly-operated National Ambulance Service (NAS) to provide ambulance services, awaited enactment (still remained a Bill as of 22-January-2015).

4. This Bill provided the legal framework to specify standards, regulate operations and enforce correct practices as well as discourage inappropriate ambulance use.

5. Together, the Ambulance Bill and Act were comprehensive, covering all critical areas of prehospital practice nationwide.

6. No specific regional legislature exists regarding prehospital practice.

7. Further legislation is needed to provide liability and legal protections offered to all tiers of first responders and trained prehospital providers. Additionally, we recommend development of legislation to regulate provider licensure and agency credentialing.

\section{DISCUSSION AND RECOMMENDA- TIONS}

The utilization of a low-resource EMS assessment framework (based on expert criteria) enabled the successful, systematic, technical conduct of this study. While NAS is a relatively young EMS agency, its development, structure, function and performance in the Ashanti Region are commendable, despite the challenging environment it operates within.

Acute and emergency conditions contributing to the Ashanti Region burden of disease, for example maternal complications, injuries from road traffic collisions, and respiratory illnesses, are amenable to NAS prehospital care to improve patient outcomes. We calculated that NAS would require a minimum additional 36 EMS units in Ashanti Region in 2012 for adequate population coverage.

Our assessment findings reveal that NAS' mostdeveloped components in the Ashanti Region include the presence of a functional lead organization, a threedigit toll-free number, a means to recruit and retain professional prehospital providers, the provision of appropriate transportation aboard well-resourced ambulances, accessibility to sustainable resources and the presence of an enabling legal framework for safe prehospital practice.

Aspects of NAS requiring the most significant development in Ashanti Region include securing a sustainable external source of revenue (outside the $\mathrm{MOH}$ ), improve public knowledge of NAS, developing a robust sustainable first-responder system, implement a robust initial and continuous medical education program, pro- 
mote community integration especially in rural areas, improve regional research, and launch a robust quality assurance and improvement program. We recommend a short and long-term strategic EMS plan to help achieve this in a coordinated, deliberate manner, in the Ashanti Region and nationally.

\section{REFERENCES}

1. World Health Organization. World Statistics. Geneva: World Health Organization, 2010. Available at:

http://www.who.int/whosis/whostat/EN_WHS10_F ull.pdf Accessed January 23, 2014.

2. Lopez AD, Mathers CD, Ezzati M, et al., editors. Global Burden of Disease and Risk Factors. Washington (DC): World Bank; 2006. Available at: http://www.ncbi.nlm.nih.gov/books/NBK11812/ Accessed January 23, 2014.

3. Razzak JA, Kellermann AL. Emergency medical care in developing countries: is it worthwhile? Bull. World Health Org. 2002;80(11):900-905.

4. Ashanti Region Health Directorate, Ghana Health Service, Ministry of Health. 2010 Half Year Report. 2011. Ashanti Region Health Directorate, Ghana Health Service, Kumasi, Ghana.

5. Komfo Anokye Teaching Hospital (KATH) Annual Report, 2009. Kumasi, Ghana.

6. Mould-Millman NK, Rominski S, Oteng R. Ambulance or taxi? High acuity prehospital transports in the Ashanti region of Ghana. Afr J Emerg Med 2014; 4(1): 8-13.

7. Forjuoh S, Mock CN, Freidman D, et al. Transport of the injured to hospitals in Ghana: the need to strengthen the practice of trauma care. Pre-hospital Immediate Care 1999; 3:66-70.

8. Nkyekyer K. Peripartum referrals to Korle $\mathrm{Bu}$ teaching hospital, Ghana - a descriptive study. Tropical Medicine and International Health. 2000;5 (11): 811-817
9. National Ambulance Service. 2010 Annual Report. 2011. Courtesy of Dr. Ahmed Zakariah. Ministry of Health, Republic of Ghana, Accra, Ghana.

10. Calvello E, Reynolds T, Hirshon JM, Buckle C, Moresky R, O'Neill J, Wallis LA. Emergency care in sub-Saharan Africa: results of a consensus conference. Afr J Emerg Med 2013; 3:42-8.

11. Mould-Millman NK, Sasser SM, Wallis LA. Prehospital research in sub-saharan Africa: establishing research tenets. Acad Emerg Med 2013; 20(12):1304-1309.

12. Osei-Ampofo M, Oduro G, Oteng R, Zakariah A, Jacquet $\mathrm{G}$, Donkor P. The evolution and current state of emergency care in Ghana. Afr $J$ Emerg Med 2013; 3[2], 52-58.

13. Kobusingye O. Emergency Medical Services, Disease Control Priorities in Developing Countries. 2006. NCBI Bookshelf. Available at: http://www.ncbi.nlm.nih.gov/books/NBK11744/ Accessed January 17, 2014.

14. Sasser SM, Varghese M, Kellermann A, Lormand JD. Prehospital trauma care systems. Geneva. World Health Organization. 2005.

15. Nielsen K, Mock C, Joshipura M, Rubiano AM, Zakariah A, Rivara F. Assessment of the status of prehospital care in 13 low- and middle-income countries. Prehospital Emergency Care. 2012; 16(3):381-9.

16. Mock C, Nguyen S, Quansah R, Arreola-Risa C, Viradia R, Joshipura M. Evaluation of Trauma Care capabilities in four countries using the WHOIATSIC Guidelines for Essential Trauma Care. World J Surg. 2006;30(6):946-56.

17. Arnold JL. International emergency medicine and the recent development of emergency medicine worldwide. Ann Emerg Med. 1999; 33(1):97-103.

18. Mould-Millman, CN., Lynch, C, Sasser, S, \& Isakov, A. Emergency Medical Technicians in Accra, Ghana: A Basic Trauma Knowledge Assessment. Annals of Emergency Medicine, 2033;58(4), S300. 